\title{
Model-Based Boost Pressure Control with System Voltage Disturbance Rejection
}

\author{
Ivan Criscuolo, Oskar Leufvén, Andreas Thomasson and Lars Eriksson
}

\section{Linköping University Post Print}

\section{Tweet}

N.B.: When citing this work, cite the original article.

Original Publication:

Ivan Criscuolo, Oskar Leufvén, Andreas Thomasson and Lars Eriksson, Model-Based Boost Pressure Control with System Voltage Disturbance Rejection, 2011, Proceedings of the 18th IFAC World Congress, 2011, 5058-5063.

http://dx.doi.org/10.3182/20110828-6-IT-1002.02214

2011 IFAC World Congress, Milano, Milano, Italy, 28 August - 2 September

Copyright: International Federation of Automatic Control (IFAC) http://www.ifac-control.org/

Postprint available at: Linköping University Electronic Press http://urn.kb.se/resolve?urn=urn:nbn:se:liu:diva-70390 


\title{
Model-based boost pressure control with system voltage disturbance rejection
}

\author{
Ivan Criscuolo* Oskar Leufvén ${ }^{* *}$ Andreas Thomasson ** \\ Lars Eriksson ** \\ * Department of Mechanical Engineering, University of Salerno, \\ Fisciano84084 Italy, icriscuolo@unisa.it \\ ** Vehicular Systems, Dept. of Electrical Engineering, Linköping \\ University, SE-581 83 Linköping, Sweden, \\ \{oleufven,andreast,larer\}@isy.liu.se
}

\begin{abstract}
Actuation systems for automotive boost control incorporate a vacuum tank and PWM controlled vacuum valves to increase the boosting system flexibility. Physical models for the actuator system are constructed using measurement data from a dynamometer with an engine having a two stage turbo system. The actuator model is integrated in a complete Mean Value Engine Model and a boost pressure controller is constructed. Based on the actuator model a nonlinear compensator, capable of rejecting disturbances from system voltage, is developed. A boost pressure controller is developed for the vacuum actuator and engine, using IMC. The complete controller is evaluated in an engine test cell where its performance is quantified and system voltage disturbance rejection is demonstrated.
\end{abstract}

Keywords: Engine, turbocharger, vacuum system, solenoid valve, internal model control, nonlinear compensator.

\section{INTRODUCTION}

The trend towards downsizing of internal combustion engines in the automotive industry has increased in recent years. The main goal is to decrease fuel consumption and emissions, while keeping the performance of the engine constant. A way of achieving this goal is the introduction of turbocharging, as proposed by Emmenthal et al. (1979), Guzzella et al. (2000), and Petitjean et al. (2004). By means of wastegate valve opening or closing, it is possible to control the flow through the turbine and thus the amount of energy available to compressor. Coordinated control of throttle and wastegate valves is important, since the control affects engine performance and efficiency, see Eriksson and Nielsen (2000) and Eriksson et al. (2002).

As turbocharging develops, the demand on the wastegate valve control strategies increases. The wastegate valve actuation is usually performed by a pressure actuator. The actuator is connected to a solenoid valve that is electronically controlled by a PWM signal in order to reach the desired pressure in the actuator chamber. One important sub problem is that the system voltage can vary several Volt during driving which has a direct influence on the performance of the boost pressure controller. Figure 1 shows that a disturbance in supply voltage from $11.9 \mathrm{~V}$ to $11.1 \mathrm{~V}$, causes an alteration in the chamber pressure of $2500 \mathrm{~Pa}$ which produces a change in wastegate valve position of about $10 \%$. The goal of this paper is to develop a boost pressure control system that follows the reference boost pressure, while also rejecting the disturbance caused by system voltage changes.

\footnotetext{
* Special thanks goes to Kristoffer Lundahl, research engineer at Vehicular Systems, for technical support.
}

\section{OUTLINE}

Section 3 briefly explains the system layout of the two stage turbocharged gasoline engine, the operating principles of the pressure relief valve and its connection to the engine. Section 4 describes the experimental data collected for modeling, together with the development of a physical including parameter identification and model validation. Section 5 presents the wastegate valve position control focusing on the nonlinear compensator, its development and the obtained results. Section 6 develops the control system for the boost pressure in order to reach the desired pressure upstream the throttle valve in the intake manifold, pointing out the supply voltage disturbance rejection. The performance of the compensator and of the control system are demonstrated first using a complete Mean Value Engine Model (MVEM) of a Two Stage TurboCharged Spark Ignition (TSTCSI) engine, developed and
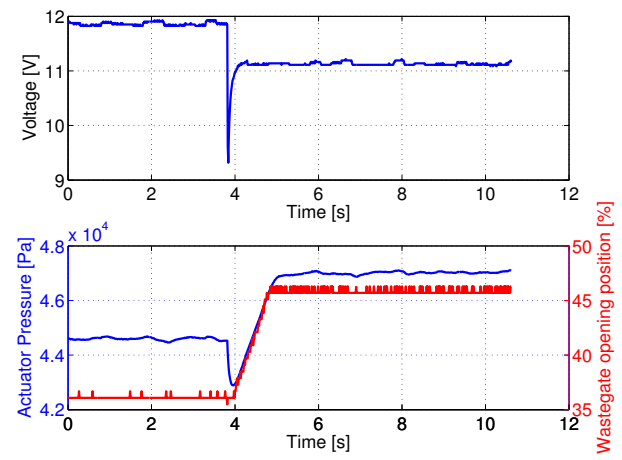

Fig. 1. Effect of voltage disturbance on actuator chamber pressure and wastegate valve position. 
validated in Eriksson (2007), and then on an engine in a test cell. Finally the conclusions are presented in section 7 .

\section{SYSTEM OVERVIEW}

Traditional turbocharged gasoline engines have a torque deficiency at low end engine speed. This comes from the trade-off between low end torque and maximum engine power since the compressor can not supply a high boost pressure over the entire engine speed range. One way to solve this problem, and get better driveability, is to use a two stage turbocharging system, allowing good performance in the full speed range of the engine.

\subsection{Engine}

The engine used for the experiments is a 2.0 liter GM four cylinder engine with direct injection, that has been equipped with a research two stage turbocharging system. Figure 2 shows a sketch of the system.

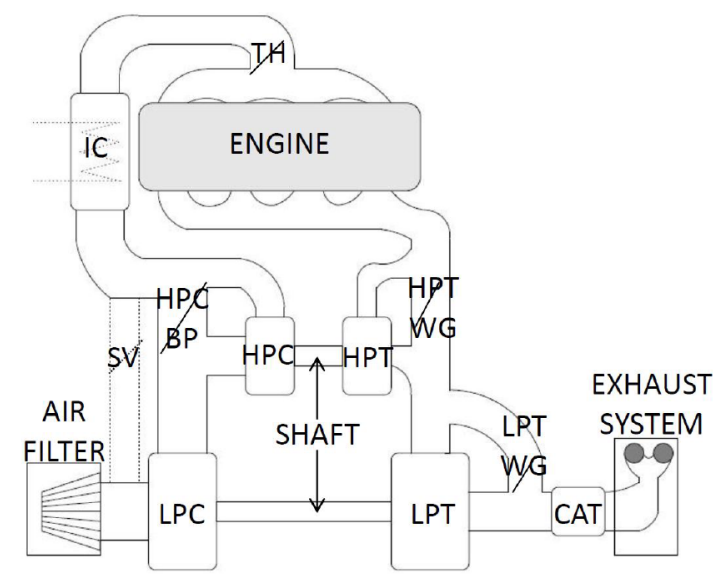

Fig. 2. Two stage turbocharging system sketch. LPC, HPC, BP, SV, IC, TH, HPT, LPT, WG and CAT mean respectively low pressure compressor, high pressure compressor, by-pass, surge valve, intercooler, throttle, high pressure turbine, low pressure turbine, wastegate and catalyst.

The advantage of this layout comes from the different sizes of the turbochargers, where the turbo of the low pressure stage is larger than the one of the high pressure stage. In this way, it is possible to utilize each turbocharger in its region of maximum efficiency. For example, in a gasoline engine it is useful to divide the engine speed range in three regions: low speed - below $2000 \mathrm{rpm}$, medium speed 2000-3500 rpm, and high speed - above $3500 \mathrm{rpm}$. In the low speed region, where the mass flow is too small to power the larger low pressure stage, the smaller turbine and the smaller inertia of the high pressure stage allows high boost pressure and fast response. At high speed the high pressure compressor goes in the choke region and thus only the low pressure stage is used. This strategy can be applied setting up the HPC by-pass valve and the HPT wastegate valve fully opened so as to completely by-pass the high pressure stage. In the middle region both turbochargers can be used in order to ensure a gradual transition between the two strategies. The operation of the wastegate and HPC bypass control valves is explained in the next section.

\subsection{Actuation system}

The main component of the actuation system is the solenoid valve that contains a plunger. The plunger position is controlled by the PWM signal and the valve is connected to other pneumatic components with three pipes, see Figure 3. On the solenoid the lowest pipe is connected to ambient air, the middle pipe to the actuator, and the top pipe to the vacuum tank.

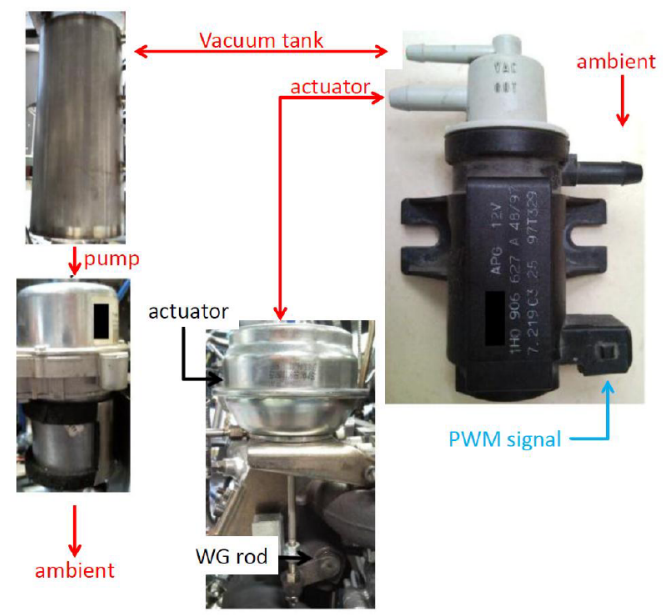

Fig. 3. Wastegate position control system scheme: the blue line represents the electrical signal, the red lines represent the pipe connections and the direction of the mass flow. The components are not to scale.

The valve controls the actuator chamber pressure and thereby the force on the membrane. Figure 4 illustrates the forces on the mechanical system that govern the membrane movement. Further, the membrane is tied to a rod connected to the wastegate shaft on the turbine. The pressure in the vacuum tank should be kept low enough to allow the membrane force to overcome the actuator spring force, allowing a fully opened and closed wastegate valve. The vacuum tank pressure is controlled by the control system, that switches on the vacuum pump when the pressure becomes too high. The reasons for tank pressure rises are leakages and plunger movement in the valve. Leakages are due to air infiltration through the ducts of the system and the elastic membrane in the solenoid valve.

Further, when the plunger is in the down position, a mass flow from actuator to tank is established increasing the tank pressure, see Figure 5. More information on plunger behavior can be found in Galindo et al. (2009) and Mehemood et al. (2010). The importance of rejecting the supply voltage disturbances is now evident. A disturbance changes the magnetic field acting on the plunger, its position and the wastegate position, changing the boost pressure. In this work, the frequency of the PWM signal was $300 \mathrm{~Hz}$, while the controller is executed at $80 \mathrm{~Hz}$.

\subsection{Experimental data}

The measurements have been performed in the engine laboratory at the Division of Vehicular Systems, Linköping University. The engine uses a rapid prototyping system from dSpace (RapidPro and MicroAutoBox), connected to 


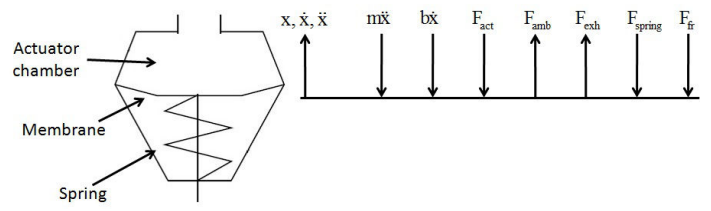

Fig. 4. Actuator working principle and forces acting on the mechanical system.

a PC running ControlDesk. In addition to the production tank pressure sensor, the system has been equipped with two extra sensors for modeling, a linear position sensor to measure the wastegate position and a sensor to measure the actuator chamber pressure.

\section{ACTUATOR MODELING}

In the next section, the methodology used to develop, identify and validate the models will be explained. The data sets for tuning and validation are different.

\subsection{Physical model}

The mass flow through the valve can be modelled with the orifice equations for compressible flow (as proposed also by Galindo et al. (2009), Ye et al. (1992) and Taghizadeh et al. (2009)). It should be noted that this model is valid for steady flows with flow states and boundary geometry being sufficiently smooth functions of a spatial variable, see e.g. Ward-Smith (1979), Sokolov and Glad (1999) and Cunningham (1951). Defining the pressure ratio as $\Pi=\frac{p_{d}}{p_{u}}$ where $p_{d}$ and $p_{u}$ are respectively the pressure downstream and upstream of the restriction and the critical pressure ratio as $\Pi_{c r i t}=\left(\frac{2}{\gamma+1}\right)^{\frac{\gamma}{\gamma-1}}$, where $\gamma$ is the specific heat ratio, the equation becomes

$$
\dot{m}=\frac{p_{u}}{\sqrt{R T}} C_{d} A \Psi(\Pi)
$$

where $C_{d}$ is the discharge coefficient, $A$ is the flow area, $R$ is the specific gas constant for air, $T$ is the temperature upstream and $\Psi(\Pi)$ is

$$
\Psi(\Pi)= \begin{cases}\Pi^{1 / \gamma}\left\{\frac{2 \gamma}{\gamma-1}\left[1-\Pi^{\frac{(\gamma-1)}{\gamma}}\right]\right\}^{1 / 2} & \text { if } \Pi \geq \Pi_{c r i t} \\ \gamma^{1 / 2}\left(\frac{2 \gamma}{\gamma+1}\right)^{\frac{\gamma+1}{2(\gamma-1)}} & \text { if } \Pi<\Pi_{c r i t}\end{cases}
$$

Equation (1) can be applied to describe the leakage in the valve as well as the plunger position when it opens a passage between ambient and actuator and between actuator and tank. With knowledge about the flows to and from the components and using the ideal gas law, we get the following equation

$$
\frac{d(p V)}{d t}=\dot{m} R T
$$

where the temperature variation is neglected. The tank is of constant volume and the tank pressure is calculated by integrating (3). To calculate the actuator pressure it is necessary to couple it to the model of the actuator, since the membrane motion causes changes in the actuator volume. The model of the actuator, and thereafter of the wastegate position, is based on Newton's second law

$$
m \ddot{x}+b \dot{x}=F_{a m b}+F_{e x h}-F_{a c t}-F_{\text {spring }}-F_{f r}
$$

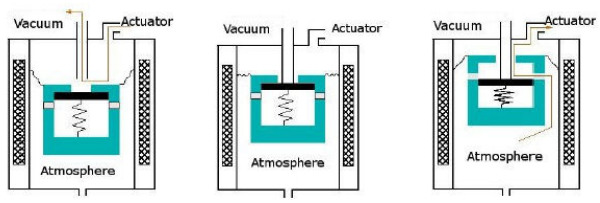

Fig. 5. Plunger movement inside soleniod valve for the three possible working position. The plunger is drawn in blue color while the component drawn whit squared black-white at extremities of the figure is the solenoid.

with the force balance as shown in Figure 4 and with the submodels described by

$$
\begin{aligned}
F_{a c t} & =p_{a c t} \cdot A_{\text {membrane }} \\
F_{\text {amb }} & =p_{a m b} \cdot A_{\text {membrane }} \\
F_{\text {spring }} & =k(x) \cdot x
\end{aligned}
$$

where $m$ is the system mass, $b$ is the damping coefficient, $F_{\text {exh }}$ is the result of the force on the wastegate plate caused by exhaust gases and $F_{f r}$ is the friction. The most popular friction model is the Dahl's model proposed by Dahl (1968) and used also by Olsson and Åström (1998), Mehemood et al. (2010), Hlouvry and Dupont (1994), and Singh and Kunt (1990):

$$
\frac{d F_{f r}}{d x}=\sigma\left(1-\frac{F_{f r}}{F_{c}} \cdot \operatorname{sign}(\dot{x})\right)^{\alpha}
$$

$F_{c}, \sigma$ and $\alpha$ determine the shape of the curve and need to be identified. This model is particularly suitable for hysteresis modeling.

\subsection{Identification and validation}

Due to the lack of plunger position measurements, and thus the passage area across the valve, the effective area $C_{d} \cdot A$ has been identified as one parameter. The plunger position depends on the force equilibrium between three main elements, force due to actuator pressure, force due to ambient pressure and force due to magnetic field. This means that the actuator pressure is strongly connected to the PWM signal. In order to identify the constants of equations (6) and (7), the least squares techniques was used on measured data.

$$
\begin{gathered}
C_{d} \cdot A=k_{1} \cdot P W M^{2}+k_{2} \cdot P W M+k_{3} \\
p_{a c t}=k_{1} \cdot P W M^{3}+k_{2} \cdot P W M^{2}+k_{3} \cdot P W M+k 4
\end{gathered}
$$

The value of the parameters $k_{i}$ can be found in Table 1 . The identified effective area for the passage from ambient to actuator is $8 \cdot 10^{-9} \mathrm{~m}^{2}$, and the passage area between actuator and tank is $10 \cdot 10^{-7} \mathrm{~m}^{2}$. Figure 6 shows a

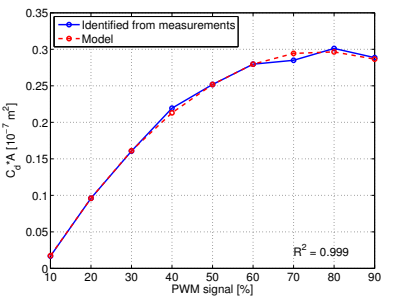

(a) Discharge coefficient for the leakage in the valve.

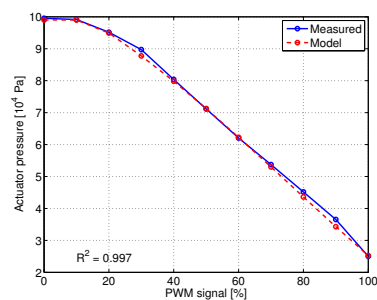

(b) Pressure in the actuator chamber.
Fig. 6. Influence of PWM signal on leakage discharge coefficient and actuator pressure. 

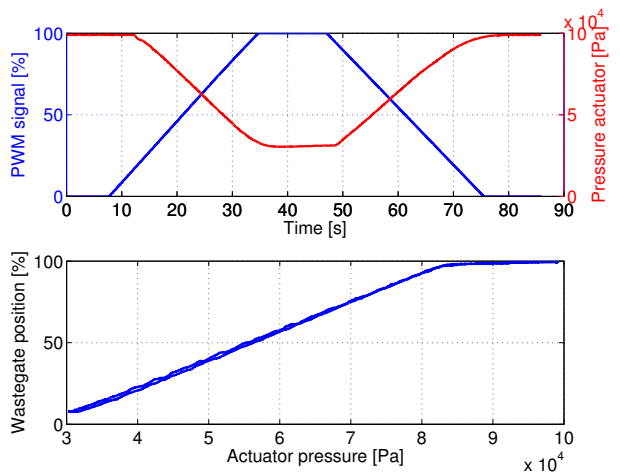

Fig. 7. Identification of hysteresis phenomenon with a updown slow ramp in PWM signal.

comparison between model and measurements, where the model is shown to give good agreement. Equation (8) manages the mass flow through the volumes of the system.

$$
\dot{m}= \begin{cases}\frac{p_{u}}{\sqrt{R T}} C_{d} A \Psi(\Pi) & \text { if } p_{u}>p_{P W M} \\ 0 & \text { if } p_{u}=p_{P W M}\end{cases}
$$

where $p_{P W M}$ is the pressure achievable depending the value of the PWM signal (see Figure 6(b)).

Table 1. Regression coefficients

\begin{tabular}{c|cc} 
& $C_{d} \cdot A$ & $p_{\text {act }}$ \\
\hline$k_{1}$ & $-4.7625 \cdot 10^{-5}$ & $2.8939 \cdot 10^{-2}$ \\
$k_{2}$ & $7.2000 \cdot 10^{-2}$ & -6.5767 \\
$k_{3}$ & $-5.2300 \cdot 10-2$ & $4.4044 \cdot 10^{2}$ \\
$k_{4}$ & & $1.0612 \cdot 10^{5}$
\end{tabular}

An analysis of experimental data shows that some approximations in the model can be assumed. In Figure 7, a slow up-down ramp was performed to analyze actuator hysteresis effects, and the result was that this effect can be neglected. The exhaust gases force is also neglected, because it has a negligible effect on the wastegate position, see Figure 8(b). An analysis of the actuator spring and the vacuum pump is then needed, to complete the model. Figure 8(a) shows that the spring has a nonlinear behavior. The lowest possible actuator pressure is the tank pressure, see Figure 9(b), and if the tank pressure is too high, the wastegate valve can not be fully actuated. To avoid this, the pressure in the tank is kept between 30 and $35 \mathrm{kPa}$ by the control system. In this region the mass flow from tank to ambient when the pump is switched on can be considered constant. A comparison between model and measurements is shown in Figure 9, for a ramp and a step in the PWM signal. Further, the dynamic behavior of the actuator and tank pressure, and actuator position are satisfactorily reproduced by the model.

\section{COMPENSATOR DEVELOPMENT}

The system voltage is expected to affect the magnetic field controlling the plunger position. Further, the plunger movement is expected to be slow compared to fast changes in the magnetic field and the plunger is therefore assumed to follow a moving average of the magnetic field. Based on experimental data the following simple compensator is proposed to handle deviations in supply voltage.

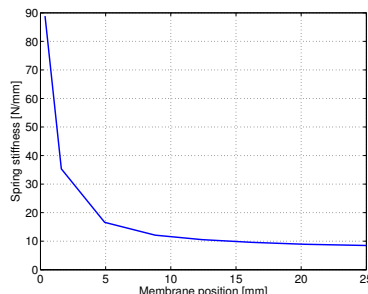

(a) Spring stiffness.

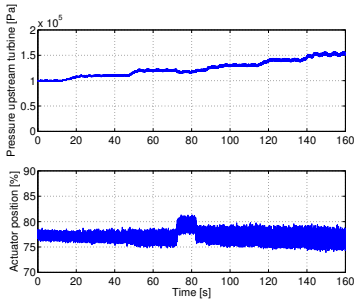

(b) $2000 \quad \mathrm{rpm}$ and $\mathrm{PWM}=50 \%$.
Fig. 8. Spring stiffness (a) and influence of force of the exhaust gases with constant PWM signal (b). The vacuum pump it switched on between $72.5 \mathrm{~s}$ and $82.2 \mathrm{~s}$, generating a voltage drop and a change in wastegate position.

$$
P W M_{\text {comp }}=\frac{12}{U} \cdot P W M_{12 V}
$$

where $P W M_{\text {comp }}$ is a compensated PWM, $\mathrm{U}$ is the supply voltage, and $P W M_{12 V}$ is the PWM value if the voltage is $12 \mathrm{~V}$. Given a desired value of wastegate position, a corresponding PWM value can be calculated using the inverse of the actuator model. A compensation for supply voltage is then calculated using Equation 9. The compensator was tested with a voltage disturbance and the results are shown in Figure 10 taking care to repeat the same shape of the voltage disturbance. Despite the voltage disturbance, appropriately modulating the PWM value with the compensator, membrane position is kept constant, verifying the performance of the compensator.

\section{BOOST PRESSURE CONTROL}

Before developing the control system, an analysis to find the best turbocharger configuration was carried out using the TSTCSI MVEM developed in Eriksson (2007). Focus was on low engine speed. The maximun boost pressure was set up to $240 \mathrm{kPa}$ to avoid engine damage and in-cylinder knocking. Two configurations, both with the throttle fully opened, were investigated: LP-wastegate fully closed and fully opened. The HP-wastegate was used to maintain constant boost pressure. Figure 11 shows that running with LP-wastegate fully closed gives maximum torque at lower engine speed. The LP-wastegate fully closed configuration is therefore used up to $2000 \mathrm{rpm}$, where the

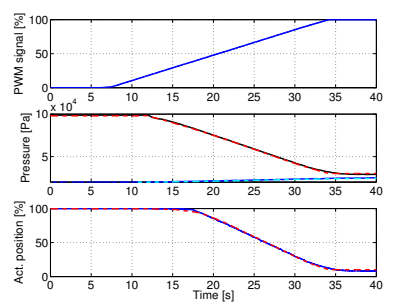

(a) PWM signal ramp.

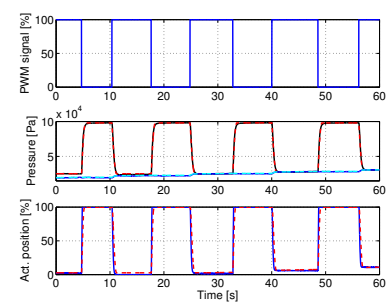

(b) PWM signal step.
Fig. 9. Validation of the model. The pressure lines represent: measured actuator pressure (black solid), model actuator pressure (red dashed), measured tank pressure (blue solid) and model tank pressure (light blue dashed). In the actuator position plot, the measured position is in blue solid and the calculated position is in red dashed. 

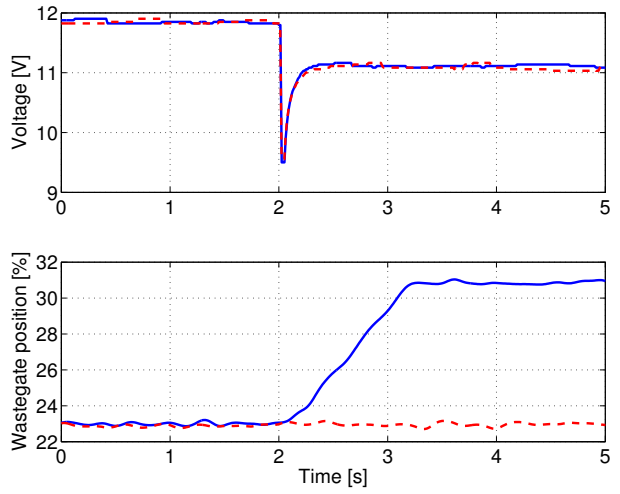

Fig. 10. Compensator performance for the supply voltage disturbance. The second plot shows the wastegate position without compensator (solid) and with compensator (dashed). The compensated wastegate position is unaffected by the supply voltage disturbance.

torque begins to decrease and the back pressure reaches too high values. The structure of the control system is shown in Figure 12, where the feedforward is a static map for PWM depending on desired boost pressure and engine speed, proposed also in Thomasson et al. (2009). To overcome the nonlinearities of the system, it was linearized across different desired boost pressures and engine speeds. Control signal step responses are then used to identify the parameters of the transfer function, which was modeled as a first order system with time delay model

$$
G(s)=\frac{K_{p}}{1+T_{t f} s} \cdot e^{-L s}
$$

where $K_{p}$ is the static gain of the system, $T_{t f}$ is the time constant and $\mathrm{L}$ is the time delay. The most common version of a transfer function for a PID controller is:

$$
C(s)=K \cdot\left(1+\frac{1}{s T_{i}}\right) \cdot\left(1+s T_{d}\right)
$$

where $\mathrm{K}$ is the proportional gain, $T_{i}$ is the integral time and $T_{d}$ is the derivative time.

The design method chosen in this work is the $\lambda$-tuning that, for noninteracting PID controllers, provides:

$$
K=\frac{1}{K_{p}} \frac{L / 2+T_{t f}}{L / 2+\lambda} ; T_{i}=T_{t f}+\frac{L}{2} ; T_{d}=\frac{T_{t f} L}{L+2 T_{t f}}
$$
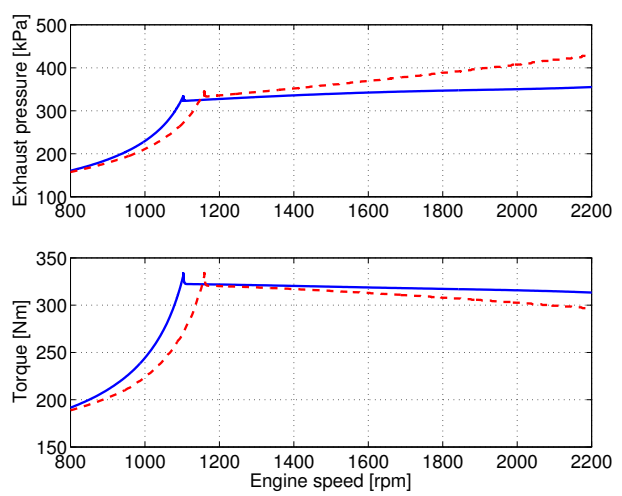

Fig. 11. Comparison between two different control strategies for low engine speed. HP-wastegate is controlled keeping respectively LP-wastegate fully closed (solid) and fully opened (dashed).

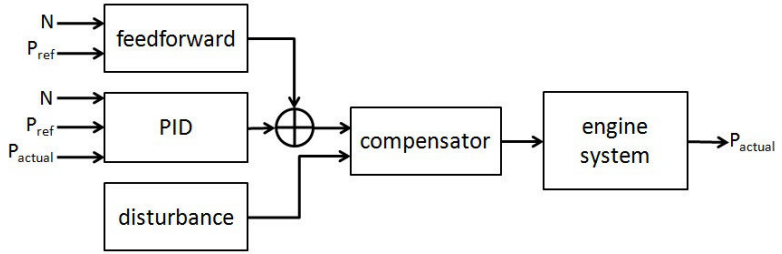

Fig. 12. Control system structure.

where $\lambda$ is the time constant describing how fast the controller will react to a control error. The derivative terms deserves a special investigation. In on-board applications instabilities could occur if the signal error, usually defined as the difference between reference and actual value $(e=$ $\left.p_{\text {ref }}-p_{\text {actual }}\right)$, processed by the derivative part is unfiltered due to high-frequency measurements noise. For this reason the signal will be filtered. This creates problems in the filtered derivative part when the reference value changes quickly. In order to avoid it, for this part only, the signal used is the process variable $P_{\text {act }}$ (Thomasson et al. (2009) and Thomasson and Eriksson (2009)). A tracking mode was added to the controller, with tracking time $T_{t r}=$ $\sqrt{T_{i} T_{d}}$, to remove the wind-up phenomenon when the control variable saturates (Åström and Hägglund, 2005).

The procedure was applied for each point of the linearization grid to achieve a gain scheduled feedback loop. A relay type controller was used to maintain the tank pressure between 30 and $35 \mathrm{kPa}$, where the controller is switched on if the pressure is higher than $35 \mathrm{kPa}$ and switched of when the tank pressure becomes lower than $30 \mathrm{kPa}$.

\subsection{Experimental controller verification}

The performance of the boost pressure control system was tested on both the MVEM model and the engine test stand. In this work only the experimental results from the test stand will be presented. The performance investigation has been divided into two steps: first the developed boost pressure controller and then the voltage compensator with the boost pressure controller. Figure 13 shows the resulting boost pressure for several steps up and down with a constant system voltage. Boost pressure follows the steps in reference value correctly. A small
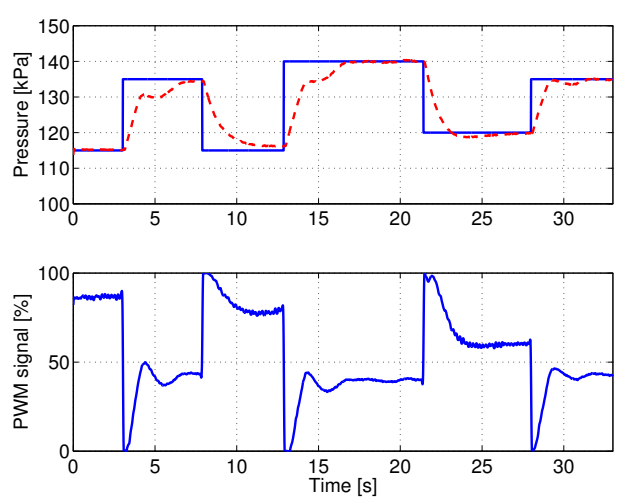

Fig. 13. Performance of the control system at $1500 \mathrm{rpm}$ subject to steps in reference value with a constant supply voltage. Upper plot: reference (solid) and actual pressure (dashed) are drawn. Lower: Corresponding PWM signal. 

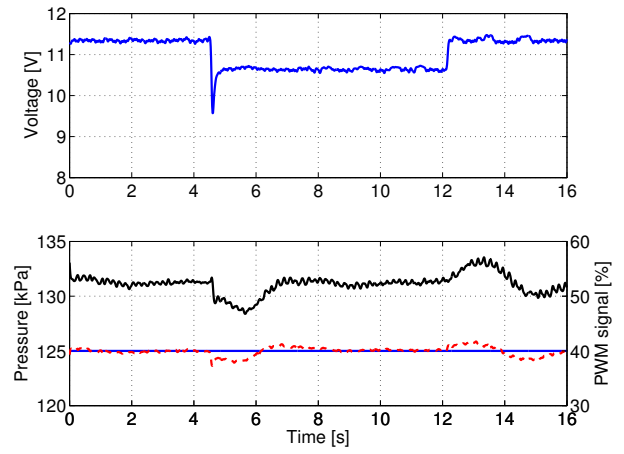

Fig. 14. Performance of the control system with the developed compensator at $1500 \mathrm{rpm}$ and a pressure set-point of $125 \mathrm{kPa}$. Upper plot: System voltage. Lower plot: PWM signal (black solid), desired (blue solid) and current (red dashed) boost pressure.

undershoot is present for a positive reference step, but it is limited to $5 \mathrm{kPa}$. The behavior is better for a reference pressure decrease, and the largest overshoot is only $1 \mathrm{kPa}$. The saturation of the PWM signal guarantees a fast response. It is worth mentioning that the controller parameters have been tuned using only the model and no retuning is made on the engine test bench.

The voltage compensator is then integrated in the engine control system. The experimental results, shown in Figure 14, point out that the simple compensator proposed is effective and the maximum pressure error is $1 \mathrm{kPa}$ $(0.8 \%)$. Since the boost pressure does not change much for variations in system voltage, this means that the wastegate position is almost constant and there is only a small movement in the membrane, proving the disturbance rejection.

\section{SUMMARY AND CONCLUSIONS}

A wastegate actuator model is developed in this paper, motivated by the need to compensate the actuactor PWM signal for supply voltage variations. The model is the foundation of a compensator for variations in actuator supply voltage. The boost pressure controller using the developed compensator is shown to give limited undershoot and overshoot, and is further able to reject the disturbance in supply voltage. The compensator is then incorporated into a boost pressure controller and the complete controller is shown to reject system voltage variations and give good boost pressure control in both MVEM simulations and in an engine test stand.

The compressible flow equations are found to be sufficient to describe the actuator system mass flow. Both discharge coefficient and static actuator chamber pressure can be modeled using polynomials in PWM signal. A simple friction model was needed to model the actuator system. Further, the actuator model shows the need to ensure low enough vacuum pressure to enable fully closed and opened actuator. A switch type controller is shown to be sufficient for vacuum tank pressure control.

\section{REFERENCES}

Åström, K.J. and Hägglund, T. (2005). Advanced PID
Control. ISA - The Instrumentation, Systems, and Automation Society.

Cunningham, R. (1951). Orifice meters with supercritical compressible flow. Trans. of the ASME, 73, 625-638.

Dahl, P. (1968). A solid friction model. Technical Report TOR-0158H3107-18I-1. The Aerospace Corporation.

Emmenthal, K., Hagermann, G., and Hucho, W. (1979). Turbocharging small displacement spark ignited angines for improved fuel economy. SAE 790311.

Eriksson, L. (2007). Modeling and control of turbocharged SI and DI engines. Oil \& Gas Science and Technology Rev. IFP, 62(4), 523-538.

Eriksson, L., Frei, S., Onder, C., and Guzzella, L. (2002). Control and optimization of turbo charged spark ignited engines. IFAC World Congress.

Eriksson, L. and Nielsen, L. (2000). Non-linear modelbased throttle control. In Electronic Engine Controls, volume SP-1500 of SAE 2000-01-0261, 47-51.

Galindo, J., Climent, H., Guardiola, C., and Domenech, J. (2009). Modeling the vacuum circuit of a pneumatic valve system. J. of Dynamic Systems, Measurement, and Control, 131(031011), 1-11.

Guzzella, L., Wenger, U., and Martin, R. (2000). ICengine downsizing and pressure-wave supercharging for fuel economy. SAE 2000-01-1019.

Hlouvry, B. and Dupont, P. (1994). A survey of models, analysis tools and compensation methods for the control of machines with friction. Automatica, 30(7), 1083-1138.

Mehemood, A., Laghrouche, S., and El Bagdouri, M. (2010). Nonlinear modeling of the VNT pneumatic actuator with aero-dynamic force. In 6th IFAC Symposium Advances in Automotive Control.

Olsson, H. and Åström, K. (1998). Friction models and friction compensation. In European J. of control.

Petitjean, D., Bernardini, L., Middlemass, C., Shahed, S., and Hurley, R. (2004). Advanced gasoline engine turbocharging technology for fuel economy improvements. SAE Technical Paper 2004-01-0988.

Singh, R. and Kunt, C. (1990). A linear time varying model for on-off valve controlled pneumatic actuators. In Trans. of the ASME.

Sokolov, A. and Glad, T. (1999). Identifiability of turbocharged IC engine models. volume SP-1451 of $S A E$ 1999-01-0216.

Taghizadeh, M., Ghaffari, A., and Najafi, F. (2009). Modeling and identification of a solenoid valve for PWM control applications. Comptes Rendus Mecanique, 337, 131-140.

Thomasson, A. and Eriksson, L. (2009). Model-based throttle control using static compensators and IMC based PID-design. IFAC Workshop on Engine and Powertrain Control, Simulation and Modeling.

Thomasson, A., Eriksson, L., Leufven, O., and Andersson, P. (2009). Wastegate actuator modeling and modelbased boost pressure control. IFAC Workshop on Engine and Powertrain Control, Simulation and Modeling.

Ward-Smith, A.J. (1979). Critical flowmetering: The characteristics of cylindrical nozzles with sharp upstream edges. Int. J. of Heat and Fluid Flow, 1(3), 123-132.

Ye, N., Scavarda, S., Betemps, M., and Jutard, A. (1992). Models of a pneumatic PWM solenoid valve for engineering applications. J. of Dynamic Systems, Measurement, and Control, 114, 680-688. 